\title{
THE INFLUENCE OF REDUCTIVE DISSOLUTION OF IRON OXIDES BY S(-II) ON URANIUM MOBILITY
}

\author{
Alexandratos V. G. ${ }^{1}$, Behrends T. ${ }^{1}$ and Van Cappellen P. ${ }^{\mathbf{1}, 2}$ \\ ${ }^{1}$ Utrecht University, Faculty of Geosciences, Department of Earth Sciences - Geochemistry P.O. Box \\ 80.021,3508TAUtrecht,The Netherlands,vasso@geo.uu.nl,behrends@geo.uu.nl,pvc@geo.uu.nl \\ ${ }^{2}$ Georgia Institute of Technology, School of Earth \& Atmospheric Sciences, Atlanta, Georgia 30332-0340, \\ USA pvc@eas.gatech.edu
}

\begin{abstract}
This study investigates possible redox transformations of uranium under transient redox conditions. Specific focus lies on the fate of $U$ as reductive dissolution of iron oxyhydroxides by S(-II) is initiated. In batch experiments sulfide was incrementally added to a lepidocrocite suspension containing adsorbed U(VI). The partitioning of uranium was monitored during the progressing transformation of lepidocrocite into FeS. Synchrotron-based X-ray absorption spectroscopy was used to resolve the oxidation state of uranium. Upon addition of sulfide intermediate release of $U$ from the solid to the solution was observed. The mobilization of $U$ was followed by immobilization in later stages. XAS reveals that this immobilization coincides with reduction of $U(V I)$ to $U(I V)$. Consequently, reduction of $U(V I)$ and precipitation of $U(I V)$ solids, due to a shift from oxic to sulfate reducing conditions is possible. However, kinetic effects might lead to an intermediate mobilization of $U$ that should be considered for the risk assessment of nuclear waste repositories and the remediation of sites, contaminated with radionuclides.
\end{abstract}

Key words: uranium mobilization, reductive dissolution, iron mineral transformation, redox transitions, iron sulfides, $X$-ray absorption spectroscopy.

\section{Introduction}

In recent years the fate of uranium in natural environments has received great attention due to the high potential of uranium migration beyond the designated waste disposal sites. Uranium contamination poses great health risks to an affected community both as a heavy metal and with the exposure to radiation as it decays. Uranium transport is mainly associated with its higher oxidation state of U(VI), considered as the uranium species with the highest solubility. In recent years, the approach of uranium immobilization as a possible in situ remediation pathway has driven numerous studies to investigate abiotic and microbial processes that induce reduction of U(VI) to U(IV), leading to uranium precipitation and thus removal from aquatic systems. Subsurface environments specifically, are characterized by ongoing changes in redox conditions that may influence not only the mobility of uranium species but also induce changes in iron mineralogy with which uranium is closely associated. The interrelationship between redox transformations of uranium and iron are very relevant in many natural environments and a subject of major importance for the remediation of sites contaminated with radionuclides and the risk assessment of nuclear waste repositories. 
Among soil minerals, iron oxides/oxyhydroxides are considered as primary sorbents for uranium due to their high reactive surface areas. Uranium sorption has been studied on goethite (e.g. Duff, 1996; Gabriel et al., 1998; Hsi and Langmuir, 1985; Giammar and Herring, 2001), on hematite (e.g. Bargar et al., 2000; Ho and Miller, 1986; Liger et al., 1999), on ferrihydrite (e.g. Waite et al., 1994; Morrison et al., 1995), on magnetite (Sagert et al., 1989) and green rust (O'Loughlin et al., 2003). In the above studies, inner-sphere complexation of uranium species with the iron mineral surfaces has been widely supported, indicating the strong sorption behavior among uranium and iron oxides. However, iron oxides can significantly influence uranium transport not only by providing reactive surfaces for uranium adsorption but they can also catalyze the reduction of U(VI) by Fe (II) (Liger et al., 1999; Lloyd et al., 2002). Mixed valence iron oxides have been proposed to be able to reduce $\mathrm{U}(\mathrm{VI})$, which has been attributed to the presence of sorbed $\mathrm{Fe}^{2+}$ (e.g. Charlet et al., 1998; Fredrickson et al., 2000; O'Loughlin et al., 2003).

Open questions still remain regarding the fate of uranium once iron oxides undergo mineral transformation with changes in the redox regime. It is known that in oxic environments uranium adsorption typically competes with carbonate complexation in solution, while under anoxic conditions reduction of U(VI) to U(IV) occurs, forming insoluble minerals (De Pablo et al., 1999; Ragnarsdottir and Charlet, 2000). Consequently, once uranium occurs in the environment as adsorbed onto iron oxides, changes in the redox regime, from oxic to anoxic, may not necessarily lead to the mobilization of uranium. However, kinetic effects might lead to the release of solid bound uranium which is not predicted by equilibrium thermodynamics. One of the most critical aftermaths of iron oxide dissolution would be the release of important -previously sorbed- pollutants such as uranium.

Overall results from previous studies lead to the hypothesis that $\mathrm{U}(\mathrm{VI})$ adsorbed to iron oxides might be mobilized when the reductive dissolution of Fe(III) is faster than the reduction of U(VI) and Fe outcompetes $\mathrm{U}$ as an oxidant for S(II). Here, we experimentally investigate the possibility of U mobilization upon reductive dissolution of iron oxides with adsorbed U(VI) by S(II), and evaluate whether U(VI) can be reduced. Efforts begin with an ideal abiotic system, imposed to anoxic conditions, where sulfide was incrementally added to a lepidocrocite suspension with preadsorbed $\mathrm{U}(\mathrm{VI})$. Lepidocrocite $(\gamma$-FeOOH$)$ was chosen for these experiments as a highly reactive iron oxide mineral which is also found in environments of altering redox conditions (Canfield, 1989). Our main purpose is to characterize the redox state and binding environment of uranium that is associated with lepidocrocite during the reaction with sulfide. Additionally the level of competition between uranium and iron reduction by sulfide will be addressed and as well as further role it could play in uranium transport within natural environments.

\section{Background Information}

During diagenesis it has been shown that bacteria play a key role in the dissolution of iron oxides by using $\mathrm{Fe}$ (III) as an electron acceptor and resulting in the production of $\mathrm{Fe}$ (II) (e.g. Lovely et al.,1991), which can be expressed by the following reaction:

$$
\mathrm{FeOOH}+\mathrm{e}^{-}+3 \mathrm{H}^{+} \rightarrow \mathrm{Fe}^{2+}+5 \mathrm{H}_{2} \mathrm{O}
$$

However, bacteria are also known to rapidly produce $\mathrm{H}_{2} \mathrm{~S}$ in organic-rich soil, which also acts as an Fe(III) reductant (Jorgensen, 1977; Canfield, 1989; Krom et al., 2002). The kinetics of reductive dissolution of iron oxides by S(-II) are well established and show a dependency on the degree of reactivity of the available iron minerals in the soil (Poulton et al., 2004; Poulton 2003; Yao and Millero, 1996; Peiffer et al., 1992; Dos Santos Afonso and Stumm, 1992). Either by using geochemical mod- 
els or through experiments, the above mentioned studies have emphasized the significance of $\mathrm{pH}$, dissolved sulfide and $\mathrm{Fe}(\mathrm{II})$ concentrations in solution and the controlling factor of mineral surface area on the rates of iron oxide dissolution.

In contrast to iron oxides, very little is known about the kinetics of $\mathrm{U}$ reduction by $\mathrm{S}(-\mathrm{II})$. As previously mentioned the abiotic reduction of $\mathrm{U}(\mathrm{VI})$ has been connected to the presence of Fe(II), however uraninite $\left(\mathrm{UO}_{2}\right)$ which has a very low solubility $\left(\mathrm{K}_{\mathrm{sp}}=10^{-60.6}\right.$; Langmuir 1978) is mostly known to form either by iron reducing bacteria (Lovley et al., 1991) of by sulfate reducing bacteria (Lovley et al., 1993; Payne at al., 2004). Nevertheless, data from several field studies from areas such as the Biscay Bay, the Cariaco Trench, the Black Sea and the Framvaren Fjord, where anoxic conditions, and thus, sulfide concentrations were extreme, gave no evidence for U(VI) reduction (Chaillou et al., 2002; Anderson et al., 1989). The reduction of $\mathrm{U}(\mathrm{VI})$ to $\mathrm{U}(\mathrm{IV})$ by a strong reductant such as $\mathrm{H}_{2} \mathrm{~S}$ should be possible, based on thermodynamics, and can possibly be expressed by the following reaction stoichiometry:

$$
\mathrm{UO}_{2}{ }^{2+}+\mathrm{HS}^{-} \leftrightarrow \mathrm{UO}_{2}+\mathrm{S}^{0}+\mathrm{H}^{+}
$$

However, most studies that achieved uranium reduction by sulphide did so only by manipulating physical or chemical parameters in laboratory experiments, e.g. by using strong sorbents that would catalyze reduction, by increasing uranium or sulfide concentrations in solution (Kochenov et al., 1977; Mohagheghi et al., 1984). Thus, evidence indicates that homogeneous reduction of U(VI) by S(-II) is kinetically hindered.

\section{Methods}

In a $\mathrm{pH}$ stat reactor $\mathrm{U}(\mathrm{VI})$ acetate was added to a lepidocrocite suspension. Synthetic lepidocrocite was produced according to the Schwertmann and Cornell (2000). Measured surface area of produced lepidocrocite was $78 \mathrm{~m}^{2} / \mathrm{g}\left(\mathrm{N}_{2}\right.$-BET analysis). No mineral phases other than lepidocrocite were identified by powder X-ray diffraction (XRD).

After adsorption equilibrium variable amounts of S(-II) (in the form of sodium sulfide solution) were added and the partitioning of uranium, changes in iron redox state, and iron oxide mineralogy were monitored. The $\mathrm{pH}$ during the reduction experiments was 8 , the ionic strength was adjusted to $0.1 \mathrm{M}$ by adding $\mathrm{NaCl}$ solution. Concentrations of dissolved elements were obtained with the use of ICP-MS or standard photometric methods after filtrating aliquots of the suspension. Depending on the macroscopic observations, fractions of the suspension were collected. The solids were recovered by centrifugation and freeze dried for X-ray adsorption spectroscopy (XAS).

For XAS solid samples were prepared as pellets and air tight sealed to avoid oxidation of reduced iron or uranium by oxygen during transportation. Collection of spectra took place at the FAME BM30M beamline, at the ESRF in Grenoble, France. XAFS spectra were recorded in the fluorescence mode at the $\mathrm{U} \mathrm{L}_{\mathrm{III}}$-edge $(\sim 17.17 \mathrm{keV})$ in a cryostat at about $30 \mathrm{~K}$. For energy calibration a $\mathrm{Y}$ foil (k-edge) was used. Titanium reduced uranium was used as a U(IV) standard and a known U(VI)-iron oxide sample for U(VI). Both X-ray absorption near-edge structure (XANES) and extended X-ray absorption fine structure (EXAFS) spectroscopy were utilized to gain insight on the oxidation state and local environment of uranium bound to the mineral surface throughout the reduction process.

All experiments and XAFS sample collection and preparation took place in an $\mathrm{O}_{2}$-free glovebox which instead contained a gas mixture of $\mathrm{N}_{2}(95 \%)$ and $\mathrm{H}_{2}(5 \%)$. The glovebox was additionally equipped with a Pd catalyst and an $\mathrm{O}_{2}$ monitor, in order to maintain and control oxygen levels below 1 ppm. All glassware used (DURAN@ ISO laboratory bottles) were previously checked for possi- 


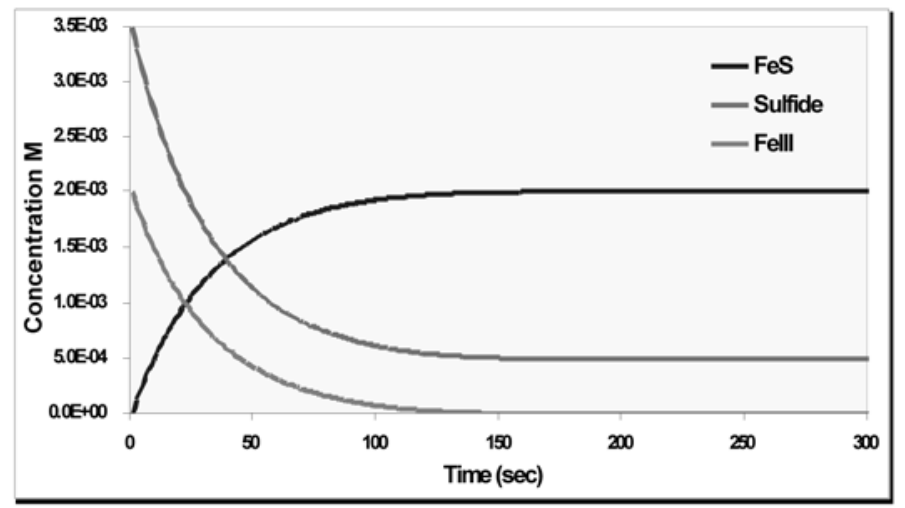

Fig. 1: Model of lepidocrocite reductive dissolution caused by sulfides.

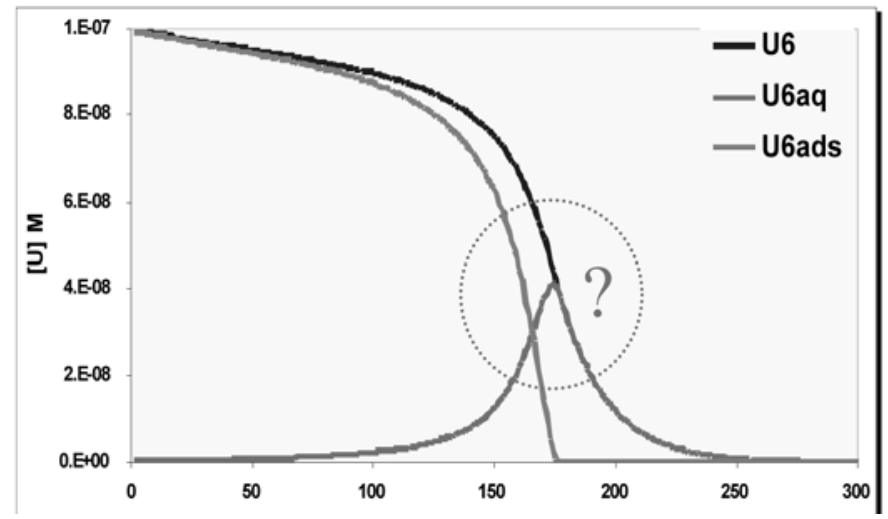

Fig. 2: Evolution of U(VI) concentration and speciation over time. The reduction of U(VI) leading to the decrease of $\mathrm{U}(\mathrm{VI})$ concentration, once $\mathrm{U}(\mathrm{VI})$ is released into solution, is fictive -indicated with question markand included in the model for illustrative purpose.

ble uranium uptake; in repeated blank absorption experiments no uranium was lost from solution. All chemicals used were of reagent grade and no further purification was performed.

In order to illustrate the role of kinetics on the mobility of uranium during reductive dissolution of iron oxides geochemical modelling was used. The rate of lepidocrocite dissolution was estimated based on the rate law and kinetic constants reported in past studies (Peiffer et al., 1991). Due to shrinking of the particles and consumption of S(II) the rate of lepidocrocite dissolution decreases with progressing reaction. For simplicity it was assumed that all produced Fe(II) precipitates as FeS. The process of complete reduction of lepidocrocite after addition of sulfide is shown in Fig. 1.

Additionally, possible pathways for the fate of $\mathrm{U}(\mathrm{VI})$ sorbed on the iron oxide mineral surface were modeled (Figure 2). The dissolution of lepidocrocite results in the release of U(VI) back into solution. $\mathrm{U}(\mathrm{VI})$ adsorption onto lepidocrocite was calculated with a simple $\mathrm{Kd}$ model. The $\mathrm{Kd}$ value was derived from adsorption isotherms which were performed prior to the dissolution experiments (data not shown). Adsorption onto FeS was not taken into account. For illustrating the possibly only temporal nature of $\mathrm{U}$ mobilization in such system re-immobilization by reduction of U(VI) was included in the calculations. In this case, relative rapid homogenous reduction of dissolved U(VI) by S(II) was assumed. 


\section{Results and Discussion}

Mineral transformation from lepidocrocite to iron sulfide occurred by the very first sulfide injection in the lepidocrocite-uranium system, an effect that was visible by the color change of the suspension from orange to black. All added S(II) was consumed within the first two hours after the initial sulfide injection, as shown in Figure 3. During this period of time, electron transfer is assumed to be taking place from the $\mathrm{Fe}$ (III) solid phase (lepidocrocite) to the sulfides that are interacting with the substrate surface. In all experiments, a second sulfide injection took place two hours after the first one, maintaining the same total concentrations of sulfide added. Consumption of S(II) occurred after the second injection as well, with the exception of experiments for which $\mathrm{S}$ (II) remained in excess in solution at the concentration level of $\sim 3 \mathrm{mM}$ (shown in Fig.3).

The progressive formation of amorphous $\mathrm{FeS}$ is assumed to dominate after the second sulfide addition, which would follow the reductive dissolution pathway described in detail by Afonso \& Stumm, (1992). Due to the fact that in these series of experiments sulfides have been added incrementally, the effects of this reduction for the system lepidocrocite-U can be observed as they follow every new sulfide addition. Reaction of lepidocrocite and S(-II) was a relatively fast process and completed within less than one hour, which agrees with the findings of Peiffer et al.(1991) and Poulton (2004). The consumption of S(-II) was predominantly coupled to the production of $\mathrm{Fe}$ (II). A notable increase in Fe(II) concentrations in both solution and solid were observed (data not shown). In all experiments $\mathrm{Fe}(\mathrm{II})$ produced is in analogy to the amount of sulfides added. In experiments where S(-II) was added in excess (e.g. Fig.3), almost all Fe(II) is produced by the very first sulfide addition.

Prior to sulfide addition to the system, the concentration of dissolved uranium (U(aq)) was below detection limits indicating the strong adsorption onto lepidocrocite (Fig. 3). Instant mobilization of U(VI) was observed with every sulfide addition. Preliminary results suggested that the instantaneous mobilization and elevated concentrations of uranium in solution after sulfide addition might be due to 1) a loss of sorption sites during iron mineral transformation 2) competition between uranium and $\mathrm{Fe}$ (II) for reactive surface sites, 3) possible formation of uranium complexes with sulfides in solution (e.g. polysulfides).

After the instantaneous increase in U(aq) concentration, induced by S (-II) addition, U(VI) concentration in solution decreased, however, approached a level significantly higher than before S(-II) addition. The decrease in U(aq) in the first hour after S(-II) addition was correlated with the S(-II) concentration. This suggests that the instantaneous mobilization of uranium might be due to formation of complexes with sulfide in solution. The elevated uranium concentrations remaining in solution after all S(-II) has been consumed after the first injection can be explained by a loss of sorption sites due to iron reduction or the competition with Fe(II) for reactive surface sites; U(VI) shows a lower affinity for $\mathrm{Fe}-\mathrm{SH}$ than for $\mathrm{Fe}-\mathrm{OH}$ groups. The release of uranium observed in all experiments reaches $\sim 5 \%$ of the total uranium added to the suspensions. Aqueous speciation of released $\mathrm{U}$ is believed to be $\mathrm{UO}_{2}{ }^{2+}$.

The decrease in $\mathrm{U}(\mathrm{aq})$ concentration after one hour of reaction time with sulfide was not accompanied with a decrease in S(-II) concentration. This re-immobilization might be caused by reduction of uranium. XANES spectra, shown in Figure 4, showed successive transformation of U(VI) into U(IV) with time. Reduction of U(VI) is in the time scale of days. We have data that supports the hypothesis that the uranium reductant is most likely not $\mathrm{S}(-\mathrm{II})_{\mathrm{aq}}$ but FeS. Hence, formation of FeS might be required for sustainable immobilization of U. Evidence for sorption and reduction of U(VI) by the crystalline sulfides galena and pyrite has been given by Wersin et al. (1994). 


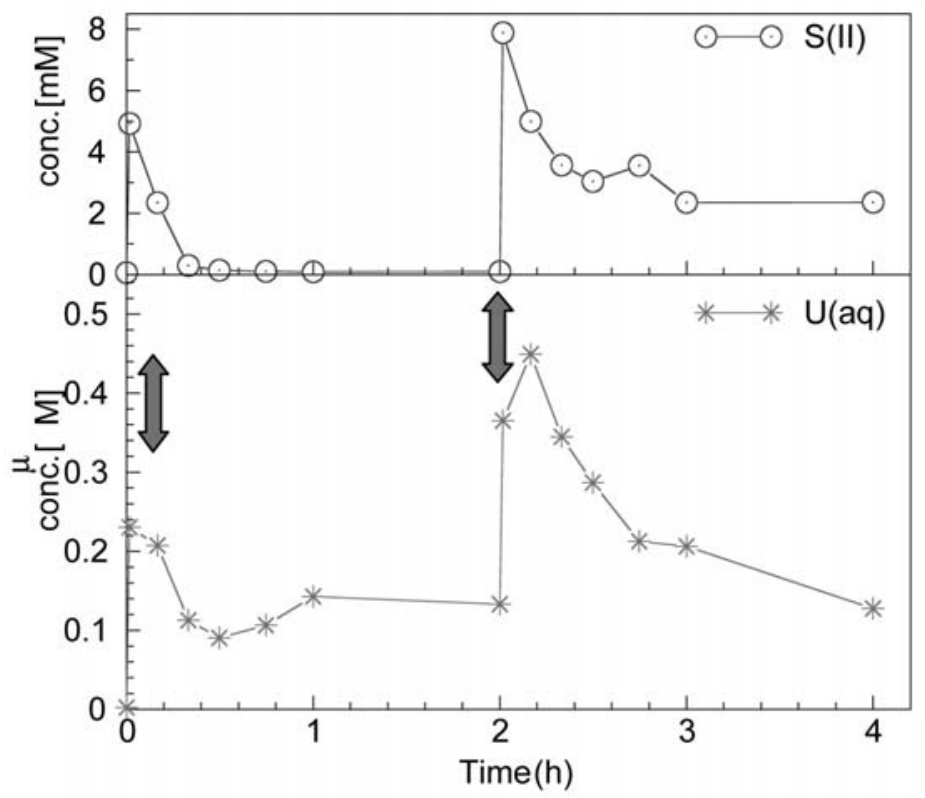

Fig. 3: Top graph shows the kinetics of S(II) consumption. The graph below shows the phase distribution of uranium in response to sulfide addition. Red arrows indicate the timings of S(II) additions.

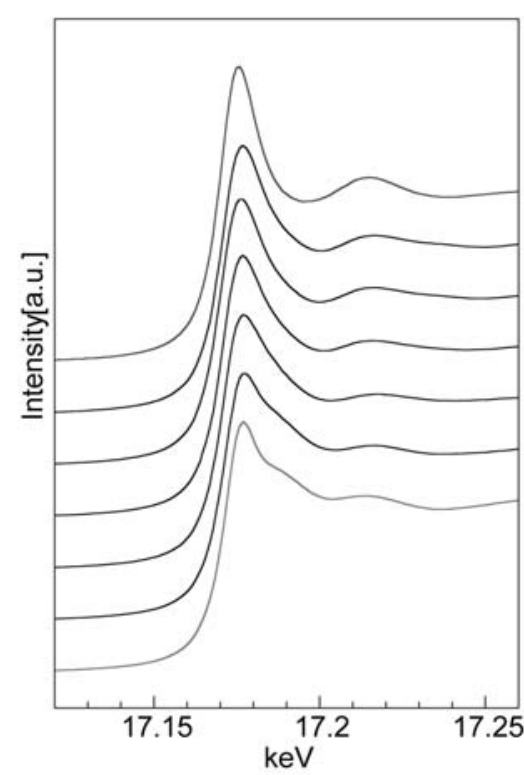

$\mathrm{U}(\mathrm{IV})$

$48 \mathrm{~h}$

$24 \mathrm{~h}$

$4 \mathrm{~h}$

$2 \mathrm{~h}$

Initial

$\mathrm{U}(\mathrm{VI})$
Fig. 4: XANES spectra showing reduction of uranium as a function of time (hours). Samples taken from the same suspension as a function of time, starting from the initial conditions (prior to sulfide additions) and following with samplings of 2, 4, 24 and 48 hours. XANES spectra are compared to standards of U(IV) (Titanium reduced uranium, with blue) and $\mathrm{U}(\mathrm{VI})$ (adsorbed to hematite, with red).

Linear combination of spectra indicated an approximate $15 \%$ presence of U(IV) in the solid sample reacted for two hours with S(-II) and an increase of $45 \%$ for the solid of 48 hours of reaction. A similar trend of progressive $\mathrm{U}(\mathrm{VI})$ reduction was observed for sample series of all other experiments. 


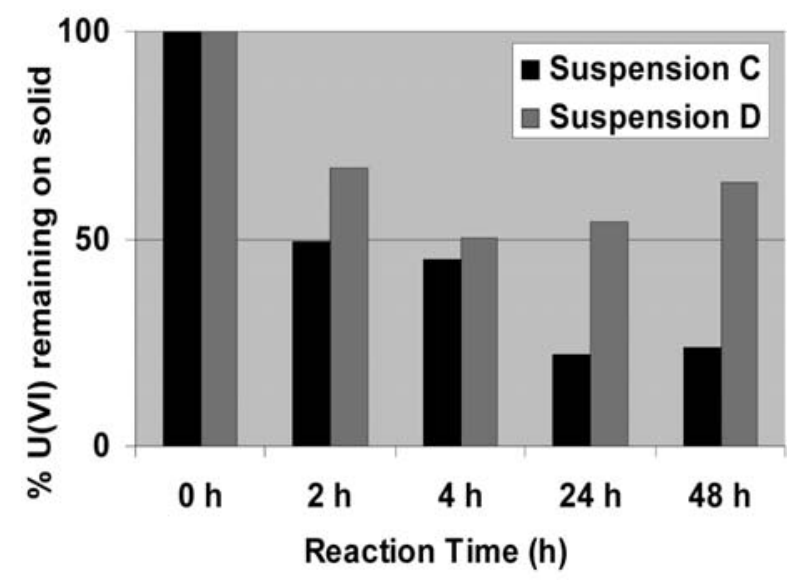

Fig. 5: Chart with U(VI) percentages remaining in association with the solid from two suspensions reacted with 8 $\mathrm{mM}$ S(-II) in "C" and $5 \mathrm{mM} \mathrm{S(-II)} \mathrm{in} \mathrm{"D".} \mathrm{Results} \mathrm{are} \mathrm{derived} \mathrm{using} \mathrm{coordination} \mathrm{numbers} \mathrm{from} \mathrm{EXAFS} \mathrm{fitting.}$

Uranium reduction is reflected in EXAFS fitting results by the decrease of axial oxygens. Coordination numbers were used to derive and compare percentages of U(VI) still remaining within the solid fraction of the collected time-series experiments. Figure 5 illustrates two of the experiments performed, indicated as "C" and " $\mathrm{D}$ ". To these suspensions $8 \mathrm{mM}$ and $5 \mathrm{mM}$ of S(-II) were added respectfully. Results show a dramatic decrease of U(VI) in suspension with the higher amount of sulfide. The formation of uraninite made its appearance much later within the duration of the experiments (data not shown). EXAFS spectra indicate U-U interactions, which are more prominent in suspensions reacted with higher amounts of S(-II) and with a greater presence of FeS. This gives us some indication that FeS is the dominant reductant for $\mathrm{U}(\mathrm{VI})$ in these systems and interactions between U(VI) with FeS might be of significant importance for controlling the mobility in environments with ongoing microbial sulfate reduction.

\section{Acknowledgments}

Authors are greateful to Dr A. Scheinost from the FZR for his assistance in the collection and analyses of XAS data as well as O. Proux and the people from the FAME beamline at the ESRF for technical support. We also thank the ESRF for funding XAS experiments but also the EU for financial support (FUNMIG).

\section{References}

Afornso, M., dos Santos and Stumm Werner, 1992. Reductive Dissolution of Iron(III) (Hydr)oxides by Hydrogen Sulfide. Langmuir, 8, 1671-1675.

Anderson, RF, Fleisher, MQ., LeHuray, AP., 1989. Concentration, oxidation state and particulate flux of uranium in the Black Sea. Geochim. Cosmochim. Acta, 53, 2215-2224.

Bargar, J. R., Reitmeyer, R., Lenhart, J. J and Davis, J.A., 2000. Characterization of U(VI)-carbonato ternary complexes on hematite: EXAFS and electrophoretic mobility measurements. Geochimica et Cosmochimica Acta, 64, No. 16, pp. 2737-2749, 2000.

Behrends, T. and Van Cappellen, P., 2005. Competition between enzymatic and abiotic reduction of ura- 
nium(VI) under iron reducing conditions. Chemical Geology 220, pp. 315-327.

Canfield, D.E., 1989. Reactive iron in marine sediments. Geochim. Cosmochim. Acta 53, 619-632

Chaillou, G., Anschutz, P., Lavaux, G., Schäfer, J. and Blanc, G., 2002. The distribution of Mo, U, and $\mathrm{Cd}$ in relation to major redox species in muddy sediments of the Bay of Biscay. Marine Chemistry 80: 41-59

Charlet, L., Silvester, E., and Liger, E., 1998c. N-compound reduction and actinide immobilisation in surficial fluids by $\mathrm{Fe}(\mathrm{II})$ : the surface $\mathrm{Fe}(\mathrm{III}) \mathrm{OFe}(\mathrm{II}) \mathrm{OH}$ degrees species, as major reductant. Chemical geology, vol.151 iss.1-4, pg.85 -93.

De Pablo, J., Casas, I., Gimenez, J., Molera, M., Rovira, M., Duro, L., and Bruno, J., 1999. The oxidative dissolution mechanism of uranium dioxide. I. The effect of temperature in hydrogen carbonate medium. Geochim. Cosmochim. Acta 63, 3097-3103.

Duff, M.C. and Amrhein, C., 1996. Uranium(VI) adsorption on goethite and soil in carbonate solutions. Soil Sci.Soc. Am. J. 60, 1393.

Fredrickson, J.K., Zachara, J.M., Kennedy, D. W., Duff, M. C., Gorby, Y. A., Li, S. M. W., and Krupka, K.M., 2000. Reduction of U(VI) in goethite (alpha-FeOOH) suspensions by a dissimilatory metal-reducing bacterium. Geochim. Cosmochim. Acta 64, 3085-3098.

Gabriel, U., Gaudet, J. P., Spadini, L., and Charlet, L., 1998. Reactive transport of uranyl in a goethite column: an experimental and modeling study. Chem. Geol., 151, 107-28.

Giammar, D.E and Herring, J.G., 2001. Time scales for sorption-desorption and surface precipitation of uranyl on goethite. Environ. Sci. Thechnol.35,3332-3337

Hsi C.-K. D. and Langmuir, D., 1985. Adsorption of uranyl onto ferric oxyhydroxides: Application of the surface complexation site-binding model. Geochim. Cosmochim. Acta 49, 1931-1941.

Ho, C. H. and Miller, N. H., 1986. Adsorption of uranly species from bicarbonate solution onto hematite particles. J. Colloid Interf. Sci. 110, 165-171.

Jørgensen, B. B., 1977. The sulfur cycle of a coastal marine sediment (Limfjorden, Denmark). Limnol. Oceanogr. 5, 814-832.

Krom, M. D., Mortimer, R. J. G., Poulton, S. W., Hayes, P., Davies, I. M., Davison, W., and Zhang, H., 2002. In-situ determination of dissolved iron production in recent marine sediments. Aquatic Sciences 64, 282-291.

Langmuir, D., 1978. Uranium solution-mineral equilibria at low temperatures with application to sedimentary ore deposits. Geochim. Cosmochim. Acta 42, 547-569.

Liger, E., Charlet, L. and Van Cappellen, P., 1999. Surface catalysis of uranium (VI) reduction by iron(II). Geochim. Cosmochim. Acta, 63, 2939-2955.

Lloyd, J. R., Chesnes, J., Glasauer, S., Bunker, D. J., Livens, F. R., and Lovley, D. R., 2002. Reduction of actinides and fission products by Fe(III)-reducing bacteria. Geomicrobiology Journal 19(1), 103-120.

Lovely, D. R., Phillips, E. J. P., Gorby, Y. A., and Landa, E. R., 1991 . Microbial reduction of uranium. Nature 350, 413-416.

Lovley, D. R., Roden, E. E., Phillips, E. J. P., and Woodward, J. C., 1993. Enzymatic Iron and Uranium Reduction by Sulfate-Reducing Bacteria. Mar. Geol. 113, 41-53.

Mohagheghi, A., Updegraff, D. M., Goldhaber, M. B., 1984. The role of sulfate-reducing bacteria in the deposition of sedimentary uranium ores. Geomicrobiology Journal. 4(2): 153-173

Morrison, S. J., Spangler, R. R., and Tripathi, V. S., 1995a. Adsorption of U(VI) on Amorphous Ferric Oxyhydroxide at High-concentrations of Dissolved Carbon (IV) and sulphur (VI). Journal of Contaminant Hydrology 17, 333-346. 
Morse, J. W. and Choppin, G. R., 1991. The chemistry of transuranic elements in natural waters. Rev. Aquatic Sci. 4, l-22.

O’Loughlin, E.J., Kelly, S.D., Cook R. E., Csencsits R., Kemner K.M., 2003. Reduction of uranium(VI) by mixed iron(II)/iron(III) hydroxide (green rust): Formation of UO2 nanoparticles. Environ. Sci. Technol.37, 721-727.

Payne, T. E., Davis, J. A., and Waite, T. D., 1994. Uranium Retention by Weathered Schists - The role of Iron Minerals. Radiochimica Acta, 297 -303.

Poulton, S. W., M. D. Krom, and R. Raiswall, 2004. A revised scheme for the reactivity of iron (oxyhydr)oxide minerals towards dissolved sulfide. Geochim. Cosmochim. Acta 68:3703-3715.

Poulton, S.W., 2003. Sulfide oxidation and iron dissolution kinetics during the reaction of dissolved sulfide with ferrihydrite. Chemical Geology, 202, 79-94.

Peiffer, S., Afonso, M., Wehrll, B., Gachter, R., 1992. Kinetics and Mechanism of the Reaction of H2S with Lepidocrocite. Environ. Sci.Technol., 26, 2408-2413.

Ragnarsdottir, KV., and Charlet, L., 2000. Uranium behaviour in natural environments. In Cotter-Howells JJ, Batcherder M, Campbell L, Valsami-Jones E, eds, Environmental Mineralogy: Microbial Interactions, Antropogenic Influences, Contaminated Lands and Waste Management, Series 9. Mineralogical Society of Great Britain and Ireland, London, UK, pp 333-377.

Sagert, N. H., Ho, C. H., and Miller, N. H., 1989. The Adsorption of Uranium(VI) onto a Magnetite Soil. Journal of Colloid and Interface Science 130, 283-287.

Schwertmann, U. and Cornell, R. M., 1991. Iron Oxides in the Laboratory - Preparation and Characterization; VCH: New York, Chapters 5-6, pp 61-84.

Waite, T. D., Davis, J. A., Payne, T. E., Waychunas, G. A., and Xu, N., 1994. Uranium(VI) adsorption to ferrihydrite: Application of a surface complexation model. Geochim. Cosmochim. Acta 58, 54655478 .

Wersin, P. Jr., Peresson, P., Redden, G., Leckie, J. O., Harris, D. W., 1994 Interaction between aqueous uranium (VI) and sulfide minerals: Spectroscopic evidence for sorption and reduction., Geochim. Cosmochim. Acta 58, 2829-2843.

Yao, W. and Millero, F. J., 1996. Oxidation of hydrogen sulfide by hydrous Fe(III) oxides in sea water. Mar. Chem. 52, 1-16. 